Original article

\title{
The interplay of etiological knowledge and mental illness stigma on healthcare utilisation in the community: A structural equation model
}

\author{
N. Schnyder ${ }^{a, *}$, C. Michel ${ }^{\mathrm{a}, \mathrm{b}}$, R. Panczak ${ }^{\mathrm{c}}$, S. Ochsenbein ${ }^{\mathrm{a}}$, B.G. Schimmelmann ${ }^{\mathrm{a}, \mathrm{d}}$, \\ F. Schultze-Lutter ${ }^{\mathrm{a}, \mathrm{e}}$ \\ a University Hospital of Child and Adolescent Psychiatry and Psychotherapy, University of Bern, Bern, Switzerland \\ ${ }^{\mathrm{b}}$ Developmental Clinical Psychology Research Unit, Faculty of Psychology and Educational Sciences, University of Geneva, Geneva, Switzerland \\ ${ }^{\mathrm{c}}$ Institute of Social and Preventive Medicine, University of Bern, Bern, Switzerland \\ ${ }^{\mathrm{d}}$ University Hospital of Child and Adolescent Psychiatry, University Hospital Hamburg-Eppendorf, Hamburg, Germany \\ e Department of Psychiatry and Psychotherapy, Medical Faculty, Heinrich-Heine-University, Düsseldorf, Germany
}

\section{A R T I C L E I N F O}

\section{Article history:}

Received 6 September 2017

Received in revised form 21 December 2017

Accepted 30 December 2017

Available online 6 March 2018

\section{Keywords:}

Attitudes

Stigma

Help-seeking

Mental health literacy

Mental problems

\begin{abstract}
A B S T R A C T
Background: The stigma of mental illness, especially personal attitudes towards psychiatric patients and mental health help-seeking, is an important barrier in healthcare utilisation. These attitudes are not independent of each other and are also influenced by other factors, such as mental health literacy, especially the public's causal explanations for mental problems. We aimed to disentangle the interrelations between the different aspects of stigma and causal explanations with respect to their association with healthcare utilisation.

Methods: Stigma and causal explanations were assessed cross-sectional using established German questionnaires with two unlabelled vignettes (schizophrenia and depression) in a random-selection representative community sample ( $\mathrm{N}=1375$, aged $16-40$ years). They were interviewed through a prior telephone survey for current mental disorder $(n=192)$ and healthcare utilisation $(n=377)$. Structural equation modelling was conducted with healthcare utilisation as outcome and stigma and causal explanations as latent variables. The final model was additionally analysed based on the vignettes. Results: We identified two pathways. One positive associated with healthcare utilisation, with high psychosocial stress and low constitution/personality related causal explanations, via positive perception of help-seeking and more help-seeking intentions. One negative associated with healthcare utilisation, with high biogenetic and constitution/personality, and low psychosocial stress related explanations, via negative perception of psychiatric patients and a strong wish for social distance. Sensitivity analysis generally supported both pathways with some differences in the role of biogenetic causal explanation. Conclusion: Our results indicate that campaigns promoting early healthcare utilisation should focus on different strategies to promote facilitation and reduce barriers to mental healthcare.
\end{abstract}

(c) 2018 Elsevier Masson SAS. All rights reserved.

\section{Introduction}

Mental disorders are treatable and potentially preventable [1-3]. Yet, they continue to be prevalent and to cause significant personal and societal costs and burdens [4-6], because help-seeking is often delayed or absent $[7,8]$. Therefore, many approaches to improve mental health focus on understanding and improving help-seeking for mental problems on population level $[9,10]$. Of the multiple barriers towards help-seeking for mental disorders [11-19], negative,

\footnotetext{
* Corresponding author at: University Hospital of Child and Adolescent Psychiatry and Psychotherapy, University of Bern, Bolligenstrasse 111, 3000, Bern 60, Switzerland.

E-mail address: nina.schnyder@upd.unibe.ch (N. Schnyder).
}

stigmatising attitudes as well as knowledge about mental (ill-)health and its treatment, i.e., mental health literacy (MHL), are important interconnected factors $[13,19]$ that, however, have not been studied together for their impact on healthcare utilisation.

The term "stigma" comprises public and personal attitudes and behavioural responses towards people with mental problems and towards help-seeking for mental disorders that are formed by cognition and affect $[20,21]$. A recent meta-analysis identified two aspects of mental disorder-related stigma associated specifically with actual help-seeking, i.e., healthcare utilisation, in the general population: personal attitudes towards individuals with mental disorders (PersonS) and attitudes towards mental health help-seeking (HelpA) [19]. Both these attitudes consist of a cognitive-behavioural and cognitive-affective component differentially related to help-seeking. The cognitive-behavioural aspect of 
PersonS is often measured as a wish for social distance from persons with a mental disorder (WSD) [22], whereas the cognitive-affective aspect of Persons is often measured as perceived dangerousness of persons with mental disorder [22,23]. WSD consistently showed negative associations with help-seeking [24,25], while cognitiveaffective aspects including perceived dangerousness did not show direct associations with help-seeking [26,27] but mediated the former relationship [28]. The cognitive-affective aspect of HelpA includes assumed feelings such as embarrassment about one's own hypothetic or actual help-seeking or what others might think about one's own hypothetic or actual help-seeking for mental problems [29]. The cognitive-behavioural aspect of HelpA includes helpseeking intentions and people's willingness to seek help in case of mental problems $[29,30]$. Similar to Persons and in line with the theory of planned behaviour [31,9], the cognitive-behavioural, but not the cognitive-affective aspect of HelpA, was related to healthcare utilisation $[32,33]$.

The different stigmatising attitudes, however, are neither exclusive nor distinct determinants of help-seeking but interact with other determinants, an important one being MHL [34]. MHL is defined as knowledge about mental disorders, including etiological and help-seeking knowledge $[35,36]$. The public's causal explanations for mental health problems as part of MHL were associated with stigmatising attitudes toward individuals with mental disorders [37]. Of these, biogenetic causal explanations were repeatedly related to more stigmatisation in terms of perceived dangerousness that, in turn, increased WSD [38,39].

Despite the wealth of knowledge on single associations between stigma, MHL and help-seeking from predominately cross-sectional studies, at present, little is known about the interplay of the various effects of stigma, biogenetic, and other causal explanations with respect to their influence on healthcare utilisation for mental problems. Furthermore, to the best of our knowledge, studies of the interrelations between causal explanations and help-seeking attitudes, as well as between help-seeking intentions and healthcare utilisation are still missing. A better integration and extension of these different cross-sectional findings, however, is needed to advance the development of combined information and anti-stigma campaigns and avoid unexpected adverse effects. This will help overcome the two important barriers to adequate and timely mental healthcare utilisation for mental problems [41-44].

Using structural equation modelling (SEM) that enabled us to account for potential correlations and associations between these constructs [40], we therefore aimed to disentangle these various interrelations between aspects of stigma and causal explanations, as possibly the most influential aspect of MHL on stigma, on hypothetical help-seeking intentions and, finally, healthcare utilisation for any mental problem at population level.

\section{Method}

\subsection{Study design}

Our study is based on the cross-sectional data of an add-on to the 'Bern Epidemiological At-Risk' (BEAR) study, a randomselection representative population telephone study in the semi-rural Canton Bern, Switzerland [45]. Between June 2011 and June 2015, we recruited participants between 16 and 40 years. We chose this age range because most axis-I mental disorders have their onset after 15 and before 41 years [46]. Besides appropriate age, eligibility criteria were main residency in Canton Bern (i.e. having a valid address in Canton Bern, and not abroad during the assessment period) and an available telephone number. Exclusion criteria included past or present psychosis, and insufficient language skills in German, French, English, or Spanish. To increase response rate, we sent an information letter prior to the first telephone contact with study details and goals.

After each interview, we asked German-speaking participants to enrol in the add-on study and complete a questionnaire on MHL and attitudes. The questionnaires focussed on either depression or schizophrenia and were randomly posted in turn within two days at most after the phone interview. To increase response rate, we reminded participants thrice to complete the questionnaire and offered help in case of difficulties.

The ethics committee at the University of Bern approved the studies. All participants gave informed consent for both studies.

\subsection{Measures}

In the telephone interview, we assessed socio-demographic variables and current axis-I disorders with the Mini-International Neuropsychiatric Interview (M.I.N.I, [48]). Past and/or present healthcare utilisation for mental problems not restricted to mental health professional bodies and irrespective of the intensity of the contact, along with the spontaneously named problems leading to it, was assessed with the WHO Pathways-toCare questionnaire [47].

Adapted from Angermeyer et al. [49], the questionnaire of the add-on study started with an unlabelled vignette (see Appendix to Angermeyer et al. [49]) on either schizophrenia or major depression referred to in subsequent questions. For assessment of causal explanations, participants were asked to rate the 18 causes on a five-point Likert scale from $0=$ 'certainly not a cause' to $4=$ 'certainly a cause'. For assessment of the cognitive-affective aspect of Persons, participants were asked to rate 11 stereotyping attributes about the described person on a five-point Likert scale from $0=$ 'certainly not agree with' to $4=$ 'certainly agree with'. For assessment of the cognitivebehavioural aspect of Persons, participants were asked to rate their willingness to engage in seven social relationships with the described person (adapted social distance scale developed by Link et al. [50]) on a five-point Likert scale from $0=$ 'definitely willing' to 4 = 'definitely not willing'. Higher values on the PersonS scales indicated stronger stigmatising attitudes. The cognitive-affective aspect of HelpA was assessed based on the response of the participants to the following two questions: "how comfortable would you feel talking with a specialist about your personal problems' (four-point Likert scale from $0=$ 'not at all comfortable' to 3 = 'very comfortable') and 'how embarrassed would you feel if your friends knew that you seek help for an emotional problem' (four-point Likert scale from 0 = 'very embarrassed' to 3 = 'not at all embarrassed'). We assessed the cognitive-behavioural aspect of HelpA (i.e., help-seeking intentions) based on the participants potential willingness to seek help from a specialist for an emotional problem (four-point Likert scale from $0=$ 'definitely not' to 3 = 'definitely yes'). For both HelpA concepts higher values indicate positive HelpA.

\subsection{Statistical analyses}

For group comparisons of categorical or non-normally distributed continuous data, we computed $\chi^{2}$-tests or Mann-Whitney $U$ tests, respectively. Prior to the structural equation models (SEM), we computed orthogonal exploratory factor analyses (EFA) with varimax rotation on the basis of polychoric correlation matrices for participant's causal explanations and Persons, to obtain independent factors. We computed SEMs with the weighted least squares and variance adjusted estimator (WLSMV, [51]) based on diagonally weighted least squares (DWLS) for categorical variables [52]. Missing data were deleted listwise. We assessed the model fit with four commonly used indices that were as follows: the $\chi^{2}$ test, 
the comparative fit index (CFI), the standardised root mean square residual (SRMR), and the root-mean-square error of approximation (RMSEA) including 90\%-confidence interval (90\%CI). A nonsignificant $\chi^{2}$-test, CFI $\geq 0.95$, SRMR $\leq 0.08$, and RMSEA $\leq 0.06$ (90\%CI should not contain 0.08 ) indicated good model fit $[53,54]$. In the evaluation of model fit, we focussed on CFI, SRMR, and RMSEA, because the $\chi^{2}$-test is sensitive to sample size resulting usually in a rejected model in large samples such as ours [55].

We formed latent variables for causal explanations and for Persons according to results of the EFA, and for the cognitiveaffective aspect of HelpA 'not embarrassing/feeling comfortable', to generate the measurement models. Help-seeking intentions and past and/or present healthcare utilisation were observed variables. Following recommendations for confirmatory factor [56], we dropped items with factor loadings $\leq 0.4$ from the analyses. We computed all parameters based on standardisation of latent and manifest variables.

We first tested the hypothesised base model including all likely associations between latent and manifest variables (eFigure 1). Then we dropped latent variables with non-significant associations as well as other non-significant associations from the model. For sensitivity analysis, we analysed the final model in the two subgroups (depression and schizophrenia vignette) separately.
Finally, we included socio-demographic variables and axis-I disorder potentially confounding healthcare utilisation. Statistical analyses were done using Stata version 14 (Stata Corporation, College Station, TX, USA) and R (R Core Team) package lavaan [57].

\section{Results}

\subsection{Sample characteristics}

Of the 2683 representative participants of the telephone study, 2519 spoke German. Of these eligible participants, 1519 returned the questionnaire; thus, the response rate was $60.3 \%$ (Fig. 1).There was no indication of a response bias related to the vignette, presence of any current mental disorder, or past and/or present healthcare utilisation for mental problems. However, non-responders were mostly young males with a low education level. All response biases had a small effect size (eTable 1 ).

Of the responders, $377(24.8 \%)$ reported past and/or present healthcare utilisation for mental problems in the telephone survey (Table 1 ). Only 49 (3.2\%) reported current healthcare contact for mental problems. Healthcare utilisers were more likely older, educated females, currently meeting the criteria for a non-psychotic mental disorder (Table 1 ).

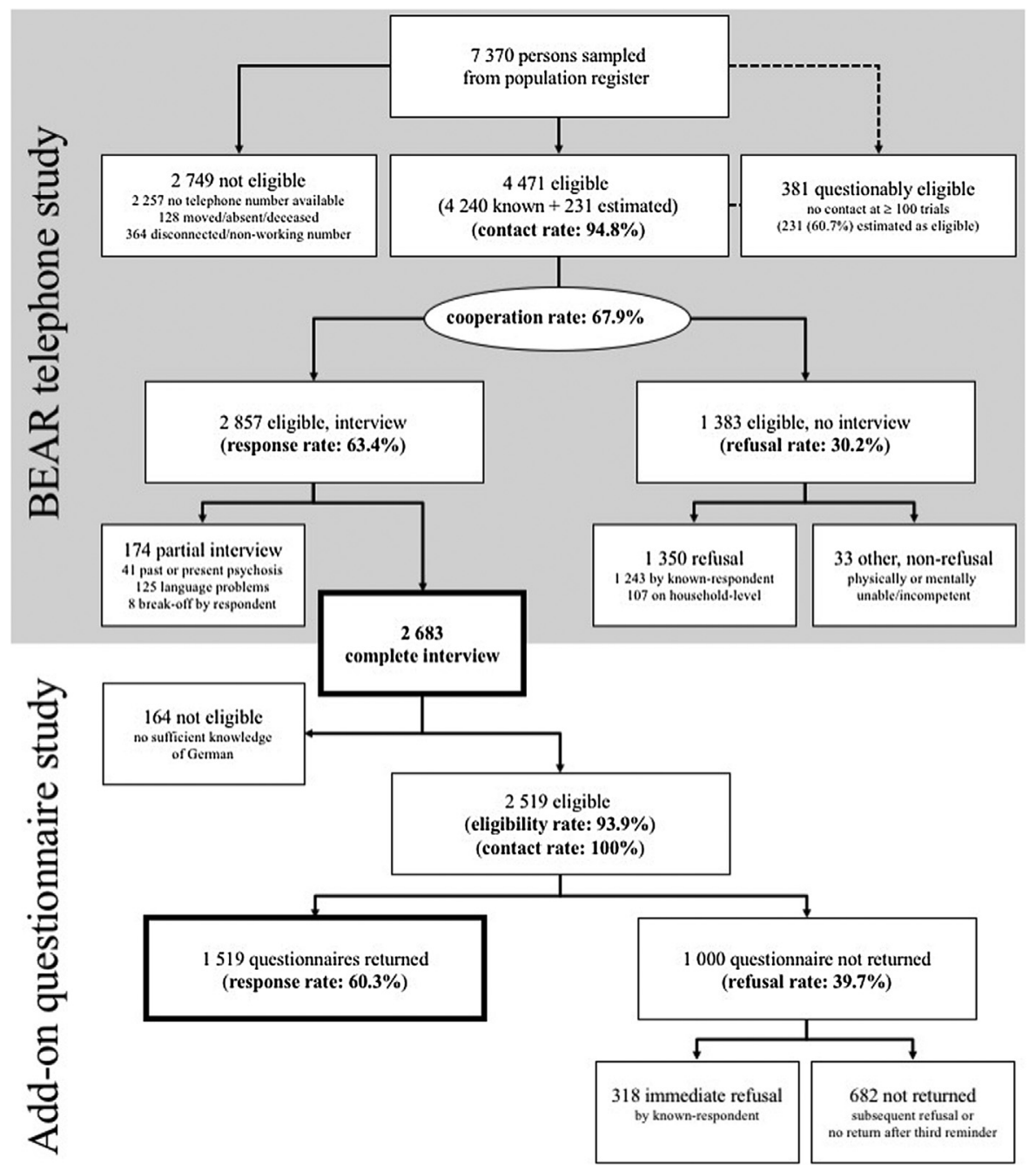

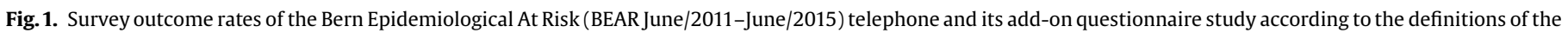

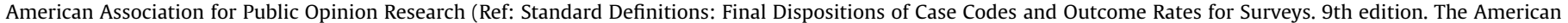

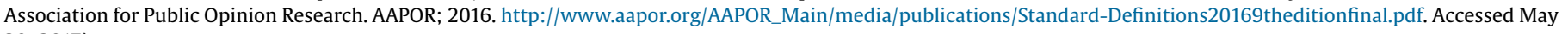
20, 2017). 
Table 1

Socio-demographic and clinical characteristics of sample.

\begin{tabular}{|c|c|c|c|c|}
\hline & $\begin{array}{l}\text { Total sample } \\
(\mathrm{N}=1519)\end{array}$ & $\begin{array}{l}\text { No past and/or present } \\
\text { healthcare utilisation } \\
(\mathrm{n}=1142 ; 75.2 \%)\end{array}$ & $\begin{array}{l}\text { Past and/or present } \\
\text { healthcare utilisation } \\
(\mathrm{n}=377 ; 24.8 \%)\end{array}$ & $\begin{array}{l}\text { Statistics } \chi^{2}(\mathrm{df}) \text { and } \\
\text { Cramer's } V^{\mathrm{c}} / U(p) \text { and } \\
\text { Pearson's } r^{\mathrm{d}}\end{array}$ \\
\hline \multicolumn{5}{|l|}{ Sex, n (\%) } \\
\hline Male & $717(47.2)$ & $603(52.8)^{*}$ & $114(30.2)^{*}$ & $\begin{array}{l}\chi_{(1)}^{2}=57.900, \mathrm{p}<0.001 \\
V=0.195\end{array}$ \\
\hline Female & $802(52.8)$ & $539(47.2)^{*}$ & $263(69.8)^{*}$ & \\
\hline Age: median (mean $\pm \mathrm{SD}$ ) & $33.9(31.3 \pm 7.3)$ & $32.9(30.8 \pm 7.4)$ & $35.3(33.0 \pm 6.6)$ & $\begin{array}{l}\mathrm{U}=179289 \cdot 5, \mathrm{p}<0.001 \\
r=0.125\end{array}$ \\
\hline \multicolumn{5}{|l|}{ Highest professional qualification ${ }^{\mathrm{a}}, \mathrm{n}(\%)$} \\
\hline Secondary school (ISCED 2) & $42(2.8)$ & $30(2.6)$ & $12(3.2)$ & $\begin{array}{l}\chi^{2}{ }_{(6)}=14.126, \mathrm{p}<0.05 \\
V=0.096\end{array}$ \\
\hline High School (ISCED 3) & $98(6.4)$ & $83(7.3)$ & $15(4.0)^{*}$ & \\
\hline $\begin{array}{l}\text { Post-secondary non-tertiary } \\
\text { education (ISCED } 4 \text { ) }\end{array}$ & $13(0.9)$ & $9(0.8)$ & $4(1.1)$ & \\
\hline Short cycle tertiary education(ISCED 5) & $794(52.3)$ & $590(51.7)$ & $204(54.1)$ & \\
\hline Doctoral (ISCED 8) & $24(1.6)$ & $13(1.1)$ & $11(2.9)^{*}$ & \\
\hline \multicolumn{5}{|l|}{ Current axis-I disorder ${ }^{\mathrm{b}}, \mathrm{n}(\%)$} \\
\hline No & $1327(87.4)$ & $1044(91.4)$ & $283(75.1)^{*}$ & $\begin{array}{l}\chi^{2}{ }_{(1)}=68.635, \mathrm{p}<0.001 \\
V=0.213\end{array}$ \\
\hline Yes & $192(12.6)$ & $98(8.6)^{*}$ & $94(24.9)^{*}$ & \\
\hline Any affective disorder & $60(3.9)$ & $14(1.2)^{*}$ & $46(12.2)^{*}$ & $\begin{array}{l}\chi^{2}{ }_{(1)}=89.996, \mathrm{p}<0.001 \\
V=0.243\end{array}$ \\
\hline Any anxiety disorder & $138(9.1)$ & $84(7.4)$ & $54(14.3)^{*}$ & $\begin{array}{l}\chi 2_{(1)}=16.662, \mathrm{p}<0.001 \\
V=0.105\end{array}$ \\
\hline Any eating disorder & $7(0.5)$ & $2(0.2)$ & $5(1.3)^{*}$ & $\begin{array}{l}\chi 2_{(1)}=8.188, \mathrm{p}<0.01 \\
V=0.073\end{array}$ \\
\hline Any somatoform disorder & $15(1.0)$ & $4(0.4)^{*}$ & $11(2.9)^{*}$ & $\begin{array}{l}\chi 2_{(1)}=19.110, \mathrm{p}<0.001 \\
V=0.112\end{array}$ \\
\hline Alcohol misuse & $18(1.2)$ & $8(0.7)$ & $10(2.7)^{*}$ & $\begin{array}{l}\chi 2_{(1)}=9.223, \mathrm{p}<0.01 \\
V=0.078\end{array}$ \\
\hline Drug misuse & $22(1.4)$ & $13(1.1)$ & $9(2.4)$ & $\begin{array}{l}\chi 2_{(1)}=3.097, \mathrm{p}=0.078 \\
V=0.045\end{array}$ \\
\hline
\end{tabular}

a according to International Standard Classification of Education (ISCED) (UNESCO Institute for Statistics, 2012 [58]).

baccording to Mini-International Neuropsychiatric Interview.

'Cramer's $V$ of $0.1,0.3$, and 0.5 represent small, medium, and large effect size.

'Pearson's $r$ of $0.1,0.3$, and 0.5 represent small, medium, and large effect size.

"cell frequency significantly higher or lower than expected with the standardised residuum of cell of $>1.96$ and of $<-1.96$, respectively.

Note: sum scores of different axis-I disorders do not add up to current axis-I disorder 'yes' due to comorbidity.

\subsection{Factors of causal explanations and stigmatising attributes}

EFA of the 18 causal explanations resulted in five independent factors: 'psychosocial stress', 'childhood adversities', 'biogenetics', 'substance abuse', and 'constitution/personality' (eTable 2). 'Psychosocial stress' was the main causal explanation for the depicted symptoms, followed by 'substance abuse', 'biogenetics', 'childhood adversities', and 'constitution/personality' (eTable 2).

EFA of the 18 items on Persons led to four independent factors as follows: 'perceived unpredictability/dangerousness', 'wish for social distance' (WSD), “dependent”, and 'needy' (eTable 3). Further analyses only considered 'perceived unpredictability/ dangerousness' and WSD due to their dominance in prior studies [59]. Participants mostly attributed unpredictability to a person with a mental disorder and expressed the strongest WSD with respect to child-care and job-recommendation (eTable 3).

Most participants expressed high help-seeking intentions, i.e. they would likely or certainly seek help in case of mental problems (eFigure 2). Participants anticipated generally feeling comfortable talking to a professional about potential mental problems, and not feeling embarrassed if others knew about the assumed helpseeking (factor 'pleasant/not embarrassing') (eFig. 2).

\subsection{Associations between causal explanations and attitudes and their influence on healthcare utilisation}

Little missing data (between $0.2-1.2 \%$ per item) resulted in $10 \%$ missing data in total, using the list wise deletion method. The initial model showed a good fit, and most hypothesised stigmatising attitudes and associations became significant (eFig. 3). No significant associations were found between causal explanations related to substance abuse or childhood adversity and 'perceived unpredictability/dangerousness' or 'pleasant/not embarrassing', and between WSD and help-seeking intentions (eFig. 3). Consequently, we dropped these two latent variables from the model and removed non-significant associations.

The final resultant SEM had a good model fit and indicated two main paths from causal explanations via attitudes to healthcare utilisation (Fig. 2,Table 2). One path was positive associated with healthcare utilisation and led from high psychosocial stress and low constitution/personality related causal explanations via perceiving help-seeking as pleasant/not embarrassing and helpseeking intentions to more likely healthcare utilisation. The other path was negative associated with healthcare utilisation and led from high biogenetic as well as constitution/personality and low psychosocial stress related causal explanations via strongly 


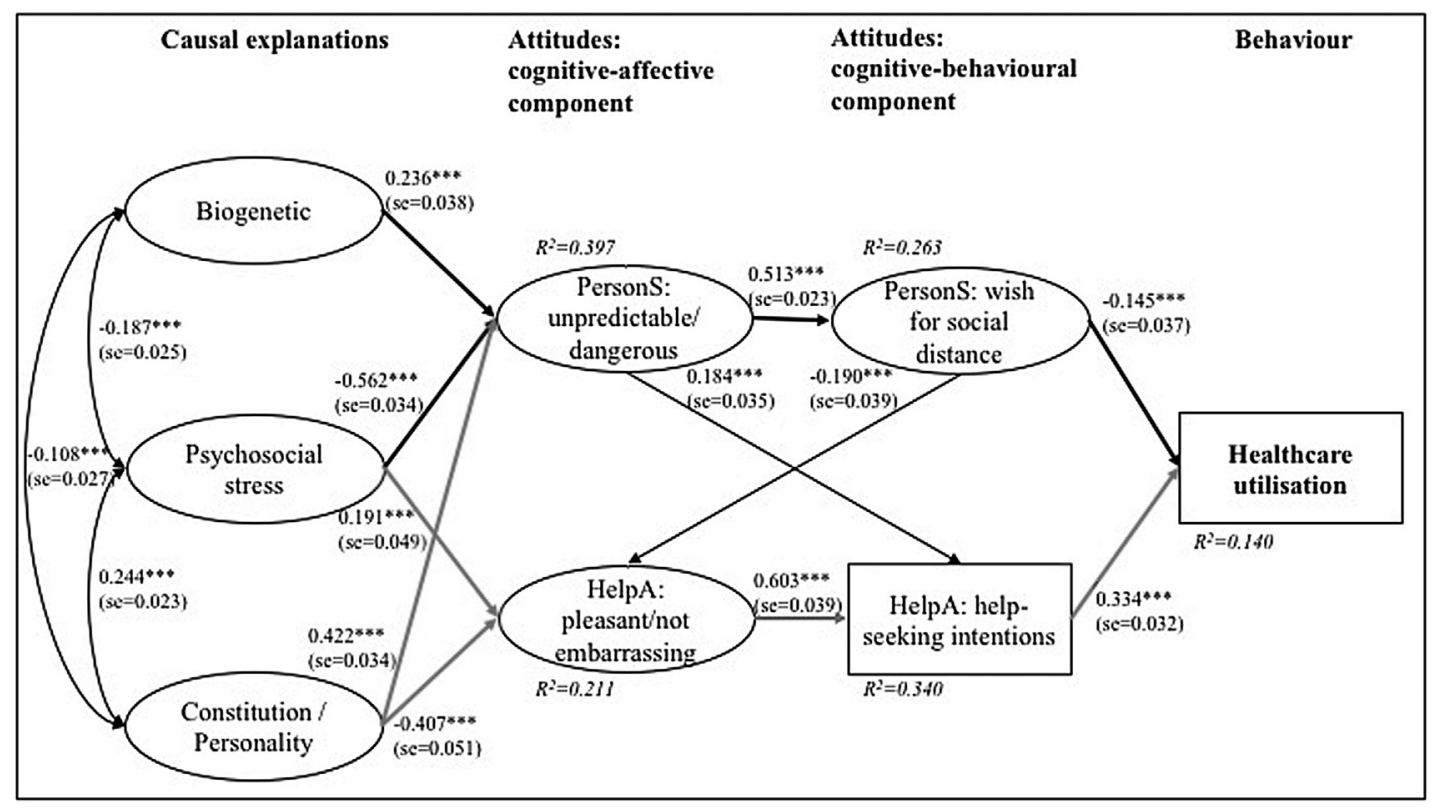

Fig. 2. Final model of associations between causal explanations, stigmatising attitudes and healthcare utilisation $(\mathrm{n}=1375$ ).

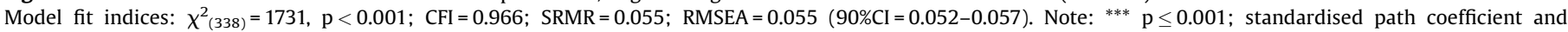



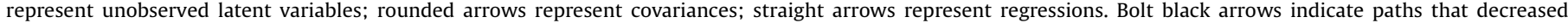
healthcare utilisation, bolt grey arrows indicate paths that increased healthcare utilisation.

perceived unpredictability/dangerousness and a strong WSD to less likely healthcare utilisation. Furthermore, a perception of unpredictability/dangerousness was positive associated with helpseeking intentions, whereas a stronger WSD was negative associated with the perception of help-seeking as pleasant/not embarrassing (Fig. 2).

\subsection{Sensitivity analyses and influence of sociodemographic and clinical variable}

The sensitivity analyses of the influence of the vignettes revealed models of comparable good fit. They differed slightly, especially with respect to the role of biogenetic causal explanations (Fig. 3). These played no significant role in the depressionvignette model. However, compared to the general model, their influence on perceived unpredictability/dangerousness became more pronounced in the schizophrenia-vignette model. The two main paths of the general model remained generally stable for both vignettes; however, for the schizophrenia vignette the association between WSD and healthcare utilisation became non-significant.

To control for potentially confounding variables of healthcare utilisation, we included socio-demographic and clinical variables in an extended SEM (eFig. 4). Although current axis-I disorder, female sex, and higher age were positively associated with healthcare utilisation and slightly increased the explained variance of healthcare utilisation, all paths of the general model (Fig. 2) remained significant at a slightly decreased model fit.

\section{Discussion}

Our unique, comprehensive community study on the pathways from causal explanations of mental disorders via attitudes towards mental disorders and help-seeking, and help-seeking intentions to healthcare utilisation provides important insights, thereby extending our knowledge on the interplay of previously reported single associations. We identified two major pathways, one that was positively associated with healthcare utilisation for mental problems and another that was negatively associated with it. These pathways were in most parts independent of the clinical picture illustrated in the two vignettes, as well as of sociodemographic variables and presence of a non-psychotic axis-I disorder.

The pathway that was positive associated with healthcare utilisation went from high psychosocial stress and low constitution/personality related causal explanations via pleasant/not embarrassing perception of help-seeking to high help-seeking intentions. Help-seeking attitudes in general (incl. help-seeking intentions) had been related to healthcare utilisation earlier [19]; however, the role of causal explanations was unknown. Interestingly, biogenetic causal explanations that received a strong focus in stigma research, especially for their effect on the attitude towards persons with mental illness $[38,39]$, played no significant role in this pathway [28]. They only exhibited relatively small negative associations with stress- and constitution/personality-related causal explanations. They have been substituted by constitution/ personality related causal explanations having a moderately negative impact on the perception of help-seeking as pleasant/ not embarrassing. Jorm and Griffiths [60] have also reported personal weakness (a main factor of our latent variable 'constitution/personality'), as opposed to biogenetic causal explanation, to be an important determinant of stigmatising attitudes. In contrast, psychosocial stress-related causal explanations with a moderately positive association with constitution/personality related explanations had a minor positive effect on help-seeking attitudes. In line with the results of previous studies [32,33], perception of helpseeking as pleasant/not embarrassing was strongly associated with help-seeking intentions, which was moderately associated with healthcare utilisation. The moderate path between intended helpseeking and healthcare utilisation supports the notion that intentions and behaviour are associated [31], but not the same. Although most people would recommend seeking help from a professional [61], a much lower proportion actually engaged in it [7]. Future studies should therefore distinguish between intended help-seeking and healthcare utilisation when examining impact of 
Table 2

Standardised factor loadings of latent variables from final model and their corresponding standard errors.

\begin{tabular}{|c|c|c|}
\hline Latent Variable Item & $\begin{array}{c}\text { Standardised factor } \\
\text { loadings }\end{array}$ & $\begin{array}{c}\text { Standard } \\
\text { error }\end{array}$ \\
\hline \multicolumn{3}{|l|}{ Causal explanations } \\
\hline \multicolumn{3}{|l|}{ Psychosocial Stress } \\
\hline Work-related stress & $0.846^{* * *}$ & 0.016 \\
\hline Problems or sorrows in family & $0.705^{* * *}$ & 0.019 \\
\hline Too high self-expectations & $0.647^{* * *}$ & 0.021 \\
\hline Severe life event & $0.523^{* * *}$ & 0.025 \\
\hline Daily hustles & $0.640^{* * *}$ & 0.021 \\
\hline \multicolumn{3}{|l|}{ Biogenetic } \\
\hline Brain disease $e^{a}$ & $1.116^{* * *}$ & 0.127 \\
\hline Heredity & $0.364^{* * *}$ & 0.046 \\
\hline \multicolumn{3}{|l|}{ Constitution/Personality } \\
\hline Weak will & $0.771^{* * *}$ & 0.027 \\
\hline Weak constitution & $0.531^{* * *}$ & 0.027 \\
\hline Immoral lifestyle & $0.539^{* * *}$ & 0.028 \\
\hline \multicolumn{3}{|l|}{ Personal Stigma (PersonS) } \\
\hline \multicolumn{3}{|l|}{$\begin{array}{l}\text { Cognitive-behavioural aspect (Wish for } \\
\text { social distance) }\end{array}$} \\
\hline $\begin{array}{l}\text { Babysit your children for a couple of } \\
\text { hours }^{\mathrm{a}}\end{array}$ & $0.764^{* * *}$ & 0.019 \\
\hline Sublet a room in your apartment & $0.748^{* * *}$ & 0.015 \\
\hline Accept as a co-worker & $0.640^{* * *}$ & 0.019 \\
\hline Accept as a neighbour & $0.789^{* * *}$ & 0.014 \\
\hline Agree on marrying into your family & $0.726^{* * *}$ & 0.016 \\
\hline Introduce to a friend & $0.697^{* * *}$ & 0.017 \\
\hline Recommend for a job & $0.675^{* * *}$ & 0.018 \\
\hline \multicolumn{3}{|l|}{ Cognitive-affective aspect (Unpredictable/ } \\
\hline Aggressive & $0.646^{* * *}$ & 0.018 \\
\hline Unpredictable & $0.698^{* * *}$ & 0.017 \\
\hline Lacking self-control & $0.737^{* * *}$ & 0.015 \\
\hline Unreasonable & $0.531^{* * *}$ & 0.022 \\
\hline Strange and different & $0.741^{* * *}$ & 0.015 \\
\hline Frightening & $0.684^{* * *}$ & 0.018 \\
\hline Dangerous & $0.788^{* * *}$ & 0.014 \\
\hline \multicolumn{3}{|l|}{ Help-seeking attitudes (HelpA) } \\
\hline \multicolumn{3}{|l|}{ Cognitive-affective aspect } \\
\hline How comfortable ${ }^{\mathrm{a}}$ & $0.552^{* * *}$ & 0.034 \\
\hline How embarrassed & $0.627^{* * *}$ & 0.036 \\
\hline
\end{tabular}

stigmatising attitudes on help-seeking, particularly if the focus is on promoting early help-seeking.

A surprising finding was the small positive effect of perceived unpredictability/dangerousness on help-seeking intentions. This association seems to depend on the strength of the perceived unpredictability/dangerousness and was only included in the sensitivity analyses for the schizophrenia vignette model [49]. This counterintuitive finding might reflect persons' wishes to prevent being stigmatised themselves by symptoms like the ones depicted in the vignette, thus voicing stronger intentions to seek help in case of their-own potential mental problems. Further studies looking deeper into this possible link are required.

The pathway that was negative associated with healthcare utilisation went from low psychosocial stress and high constitution/personality related causal explanations as well as biogenetic causal explanations via perceived unpredictability/dangerousness to high WSD. Earlier studies on the impact of causal explanations on stigma had often focussed on biogenetic causal explanations [39], while other causal models received less attention. Interestingly, despite supporting a significant moderate role of biogenetic causal explanations, our results indicated a strong role of the commonly neglected psychosocial stress and constitution/personality related causal explanations on stigmatisation of persons with mental disorder. Altogether, our results on causal explanations indicate that causal models related to person factors increase perceived unpredictability/dangerousness while those related to stressful environmental factors decrease it. In line with the results of other studies [28,38], perceived unpredictability/dangerousness increased WSD. However, this had a minor negative effect on healthcare utilisation. A recent meta-analysis reported a slightly smaller effect of attitudes towards persons with mental disorder compared to that of attitudes towards help-seeking in the general population, on healthcare utilisation [19]. Furthermore, the higher impact of help-seeking attitudes on healthcare utilisation supports the earlier theories of a strong association between the two [31,62]. In the schizophrenia vignette model, this direct link between WSD and healthcare utilisation disappeared. This was surprising in light of the commonly reported greater link of WSD with schizophrenia compared to its link with depression [49]; this was expected to exert a stronger impact on healthcare utilisation.

Contrary to our expectations, we did not find a direct association between WSD and help-seeking intention. However, WSD had a negative impact on the positive pathway because of the perception of help-seeking as potentially embarrassing/unpleasant. Other studies have shown negative effects of WSD on help-seeking intentions $[27,63]$. However, to the best of our knowledge, our study was the first to differentially assess this relationship, including the perception of help-seeking as potentially embarrassing/unpleasant, as a moderator of help-seeking intentions in one model.

The acknowledgement of two largely independent pathways from causal models via stigmatising attitudes to healthcare utilisation, if replicated in future studies with a prospective design, will be relevant to designing efficient campaigns promoting early healthcare utilisation. These could focus on reducing barriers to healthcare, promoting facilitators of health care utilisation, or both, by differential strategies. In both cases, however, childhood adversity and substance use related causal explanations seem to play a negligible role on stigma-related barriers to healthcare utilisation, at least not in cases of schizophrenia and depression. Our results indicate that these pathways, albeit sharing many features, do differ in some respects. Thus, future studies should also address the question of similarities and differences with respect to different mental disorders; this will improve the focus on common links in general campaigns and address specific features, related to specific risk groups, in special campaigns.

\subsection{Strengths and limitations}

Despite the two obvious strengths of our study: (1) examining various relevant associations of the pathway from causal models via stigmatising attitudes to healthcare utilisation in one study, and (2) using healthcare utilisation, rather than only hypothetical helpseeking intentions, as an outcome in a randomly selected, representative community sample, some limitations have to be considered. One of the limitations our study shares with other studies $[13,19]$ is its reliance on cross-sectional data of a highincome, Western society. We can therefore neither exclude the problem of reversed causation, because past healthcare utilisation might shape a person's attitudes, nor can we translate our findings to low-income or non-western societies. Another limitation shared with other studies $[64,65]$ is the possibility of a response bias towards social desirability. Future studies might use implicit association tests or direct behavioural observations. Furthermore, the small differences between the two vignette groups might indicate an effect of symptoms on healthcare utilisation. An earlier analysis of the first half of participants, however, has shown that, irrespective of the clinical picture, participants' main spontaneously reported reasons for healthcare utilisation were depressiveness (30\%) and anxiety (17\%) and related symptoms such as agitation, withdrawal, loss of energy and tension as well as interpersonal problems (27\%), which 


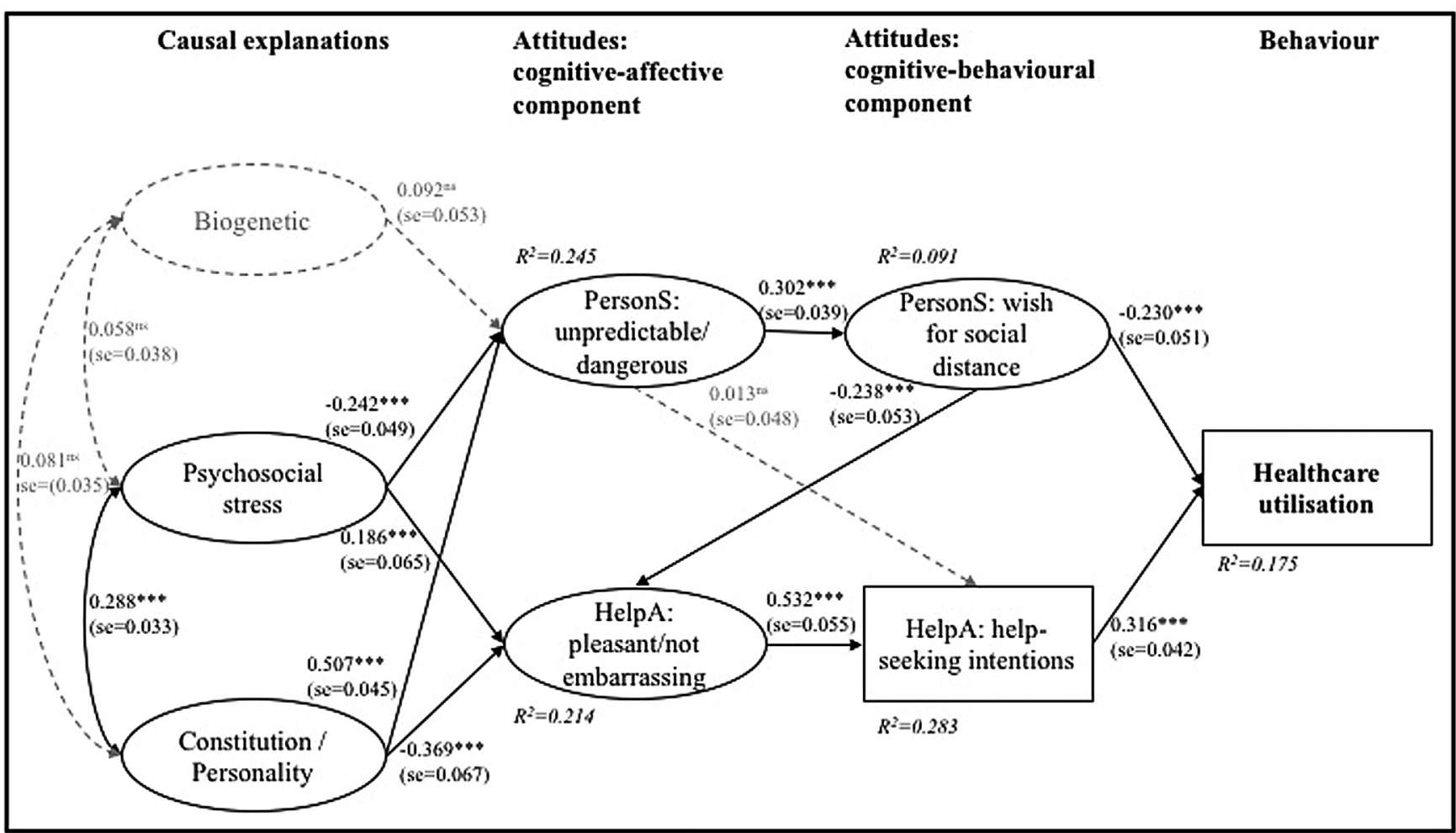

A: depression vignette only $(n=691)$.

Model fit indices $(\mathrm{MFI}): \chi^{2}{ }_{(291)}=861, \mathrm{p}<0.001 ; \mathrm{CFI}=0.957 ; \mathrm{SRMR}=0.060 ; \mathrm{RMSEA}=0.053(90 \% \mathrm{CI}=0.049-0.057)$

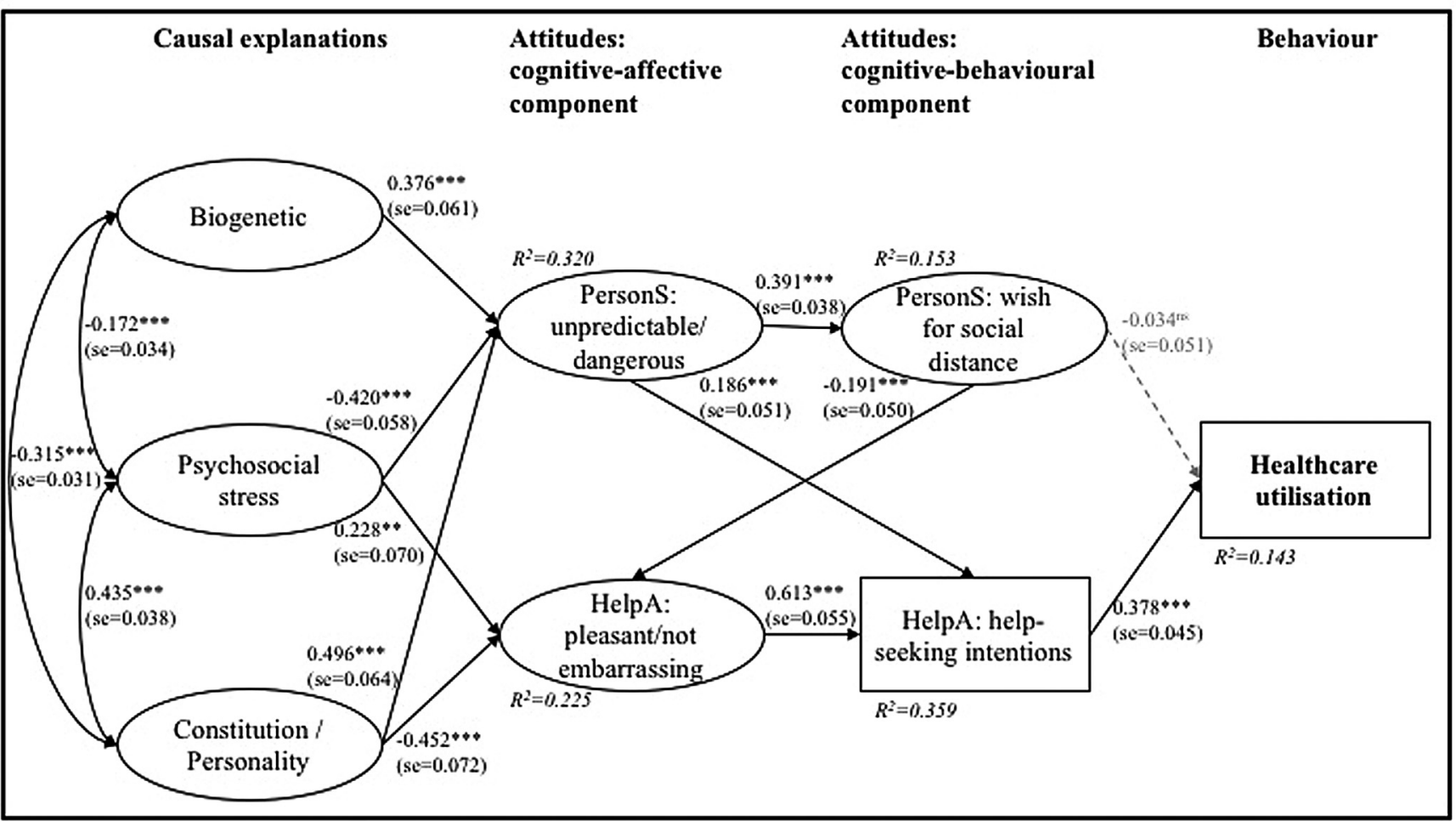

B: schizophrenia vignette only $(n=694)$.

Model fit indices: $\chi^{2}(339)=958, p<0.001 ;$ CFI $=0.956 ;$ SRMR $=0.061 ;$ RMSEA $=0.051(90 \% \mathrm{CI}=0.047-0.055)$

Fig. 3. Final model of associations for depression and schizophrenia vignette separately.

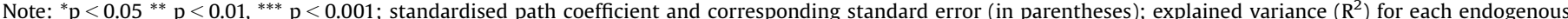

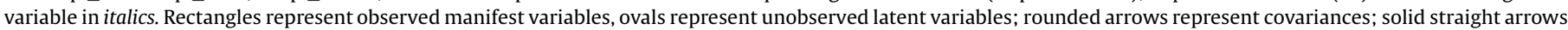

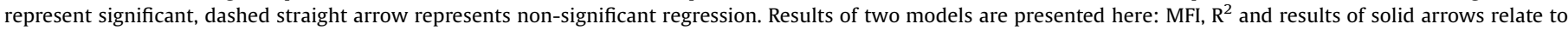
reduced model (non-significant paths dropped from model). Result of dashed arrow relates to full model. 
frequently accompany mental disorders [66]. As this is in line with other reports on symptomatic reasons for healthcare utilisation for mental problems [67], little mental problem or disorder-specific effect on help-seeking was expected, yet should be studied in future and larger studies. The explained variance of the outcome healthcare utilisation was relatively low, because other structural and/or personal barriers [11-19] will likely contribute to an individuals' complex decision to seek help and should be considered additionally in future studies. Finally, we strictly focussed on the action of seeking help for mental problems as the starting point of adequate healthcare provision for mental problems irrespective of the type of point-ofcontact and of its consequences in terms of subsequent support or referral pathways, which will also be crucial in providing early, adequate help and improve global mental health on the population level. Thus, our outcome healthcare utilisation cannot be equalled to professional mental health treatment, this limiting the impact of past healthcare utilisation on stigma and MHL. Further discussion of strengths and limitations of the study design incl. validity of assessments and choice of age range can be found elsewhere [45].

In our sample, we detected a small response bias in favour of female sex, higher age, and higher education. Since only few studies have reported potential response biases [68], we cannot estimate if other similar studies share these biases. However, they are frequently reported in general population studies $[69,70]$. Education, age, and sex had no significant impact on our outcome, thus these small biases are likely to be negligible.

\subsection{Conclusion}

Our unique study indicated the presence of two largely independent pathways from causal models via stigmatising attitudes to healthcare utilisation. The positive pathway included help-seeking attitudes, the negative pathway included attitudes towards persons with mental disorder. Interestingly, in both pathways, biogenetic causal models played only a minor role, indicating that other causal explanations should be considered equally in future studies. In line with the theory of planned behaviour [31,71], future studies should distinguish between help-seeking intentions and healthcare utilisation. They might additionally take past behaviours (e.g. past treatment) into account when examining influencing factors such as attitudes and causal explanations. Furthermore, our sensitivity analyses indicated that, while mental disorders might share certain crucial features in attitude-related barriers and facilitators, they might also be associated with distinct features that could be relevant for disorder-specific campaigns.

\section{Conflict of interest}

None.

\section{Acknowledgment}

The authors gratefully acknowledge the help and input of following researchers (in alphabetical order): L. Rietschel and S.J. Schmidt.

\section{References}

[1] Barrera AZ, Torres LD, Muñoz RF. Prevention of depression: the state of the science at the beginning of the 21 st century. Int Rev Psychiatry 2007;19:655-70.

[2] Bienvenu OJ, Ginsburg GS. Prevention of anxiety disorders. Int Rev Psychiatry 2007;19:647-54.

[3] Waddell C, Hua JM, Garland OM, Peters R Dev, McEwan K. Preventing mental disorders in children: a systematic review to inform policy-making. Can J Public Health 2007:98:166-73.

[4] Whiteford HA, Degenhardt L, Rehm J, Baxter AJ, Ferrari AJ, Erskine HE, et al. Global burden of disease attributable to mental and substance use disorders: findings from the Global Burden of Disease Study 2010. Lancet 2013;382:1575-86

[5] Gustavsson A, Svensson M, Jacobi F, Allgulander C, Alonso J, Beghi E, et al. Cost of disorders of the brain in Europe 2010. Eur Neuropsychopharmacol 2011;21:718-79.

[6] Wittchen HU, Jacobi F, Rehm J, Gustavsson A, Svensson M, Jönsson B, et al. The size and burden of mental disorders and other disorders of the brain in Europe 2010. Eur Neuropsychopharmacol 2011;2:655-79.

[7] Wang PS, Angermeyer M, Borges G, Bruffaerts R, Tat Chiu W, De Girolamo G, et al. Delay and failure in treatment seeking after first onset of mental disorders in the World Health Organization's World Mental Health Survey Initiative. World Psychiatry 2007;6:177-85.

[8] Penttilä M, Jääskeläinen E, Hirvonen N, Isohanni M, Miettunen J. Duration of untreated psychosis as predictor of long-term outcome in schizophrenia: systematic review and meta-analysis. Br J Psychiatry 2014;205:88-94.

[9] Campion J, Bhui K, Bhugra D. European Psychiatric Association (EPA) guidance on prevention of mental disorders. Eur Psychiatry 2012;27:68-80.

[10] Kalra G, Christodoulou G, Jenkins R, Tsipas V, Christodoulou N, Lecic-Tosevski $\mathrm{D}$, et al. Mental health promotion: guidance and strategies. Eur Psychiatry 2012;27:81-6.

[11] Andrade LH, Alonso J, Mneimneh Z, Wells JE, Al-Hamzawi A, Borges G, et al. Barriers to mental health treatment: results from the WHO World Mental Health surveys. Psychol Med 2014;44:1303-17.

[12] Bonabi H, Müller M, Ajdacic-Gross V, Eisele J, Rodgers S, Seifritz E, et al. Mental health literacy, attitudes to help seeking, and perceived need as predictors of mental health service use: a longitudinal study. J Nerv Ment Dis 2016;204:321-4.

[13] Clement S, Schauman O, Graham T, Maggioni F, Evans-Lacko S, Bezborodovs N, et al. What is the impact of mental health-related stigma on help-seeking? A systematic review of quantitative and qualitative studies. Psychol Med 2015;45:11-27.

[14] Corrigan PW, Druss BG, Perlick DA. The impact of mental illness stigma on seeking and participating in mental health care. Psychol Sci Public Interest 2014; $15: 37-70$

[15] Schomerus G, Angermeyer MC. Stigma and its impact on help-seeking for mental disorders: what do we know? Epidemiol Psichiatr Soc 2008;17:31-7.

[16] Thornicroft G. Stigma and discrimination limit access to mental health care. Epidemiol Psichiatr Soc 2008;17:14-9.

[17] Gulliver A, Griffiths KM, Christensen H. Perceived barriers and facilitators to mental health help-seeking in young people: a systematic review. BMC Psychiatry 2010;10:113-21.

[18] Kanehara A, Umeda M, Kawakami N. Barriers to mental health care in Japan: results from the World Mental Health Japan survey. Psychiatry Clin Neurosci 2015;69:523-33.

[19] Schnyder N, Panczak R, Groth N, Schultze-Lutter F. Association between mental health-related stigma and active help-seeking: systematic review and meta-analysis. Br J Psychiatry 2017;210:261-8.

[20] Dividio JF, Hewstone M, Glick P, Esses VM. Prejudice, stereotyping and discrimination: theoretical and empirical overview. In: Dividio JF, Hewstone, Glick MP, Esses VM, editors. Prejudice, stereotyping and discrimination. London: SAGE; 2010.

[21] Fiske ST. Stereotyping, prejudice, and discrimination. In: Gilbert DT, Fiske ST, Lindzey G, editors. The handbook of social psychology. New York: McGrawHill; 1998.

[22] Link BG, Phelan JC, Bresnahan M, Stueve A, Pescosolido BA. Public conceptions of mental illness: labels, causes, dangerousness, and social distance. Am J Public Health 1999;89:1328-33.

[23] Jorm AF, Reavley NJ, Ross AM. Belief in the dangerousness of people with mental disorders: a review. Aust N Z J Psychiatry 2012;46:1029-45.

[24] Interian A, Ang A, Gara MA, Link BG, Rodriguez MA, Vega WA. Stigma and depression treatment utilisation among Latinos: utility of four stigma measures. Psychiatr Serv 2010;61:373-9.

[25] Aromaa E, Tolvanen A, Tuulari J, Wahlbeck K. Personal stigma and use of mental health services among people with depression in a general population in Finland. BMC Psychiatry 2011;11:52-7.

[26] Cooper AE, Corrigan PW, Watson AC. Mental illness stigma and care seeking. J Nerv Ment Dis 2003:191:339-41.

[27] Schomerus G, Matschinger H, Angermeyer MC. The stigma of psychiatric treatment and help-seeking intentions for depression. Eur Arch Psychiatry Clin Neurosci 2009;259:298-306.

[28] Lee AA, Laurent SM, Wykes TL, Andren KAK, Bourassa KA, McKibbin CL. Genetic attributions and mental illness diagnosis: effects on perceptions of danger, social distance, and real helping decisions. Soc Psychiatry Psychiatr Epidemiol 2014:49:781-9.

[29] ten Have M, de Graaf R, Ormel J, Vilagut G, Kovess V, Alonso J. ESEMeD/ MHEDEA 2000 Investigators. Are attitudes towards mental health helpseeking associated with service use? Results from the European Study of Epidemiology of Mental Disorders. Soc Psychiatry Psychiatr Epidemiol 2010;45:153-63.

[30] Picco L, Abdin E, Chong SA, Pang S, Shafie S, Chua BY, et al. Attitudes toward seeking professional psychological help: factor structure and sociodemographic predictors. Front Psychol 2016;7:547.

[31] Ajzen I. The theory of planned behavior. Organ Behav Hum Decis Process 1991:50:179-211. 
[32] Mojtabai R, Evans-Lacko S, Schomerus G, Thornicroft G. Attitudes toward mental health help seeking as predictors of future help-seeking behavior and use of mental health treatments. Psychiatr Serv 2016;67:650-7.

[33] McEachan RRC, Conner M, Taylor NJ, Lawton RJ. Prospective prediction of health-related behaviours with the theory of planned behaviour: a metaanalysis. Health Psychol Rev 2011;5:97-144.

[34] Svensson B, Hansson L. How mental health literacy and experience of mental illness relate to stigmatizing attitudes and social distance towards people with depression or psychosis: a cross-sectional study. Nord J Psychiatry 2016;70:309-13.

[35] Jorm AF, Korten AE, Jacomb PA, Christensen H, Rodgers B, Pollitt P. Mental health literacy: a survey of the public's ability to recognise mental disorders and their beliefs about the effectiveness of treatment. Med J Aust 1997;166:182-6.

[36] Wei Y, McGrath PJ, Hayden J, Kutcher S. Mental health literacy measures evaluating knowledge, attitudes and help-seeking: a scoping review. BMC Psychiatry 2015;15:291-311.

[37] Reavley NJ, Jorm AF. Associations between beliefs about the causes of mental disorders and stigmatising attitudes: results of a national survey of the Australian public. Aust N Z J Psychiatry 2014;48:764-71.

[38] Schomerus G, Matschinger H, Angermeyer MC. Causal beliefs of the public and social acceptance of persons with mental illness: a comparative analysis of schizophrenia, depression and alcohol dependence. Psychol Med 2014;44:303-14

[39] Kvaale EP, Haslam N, Gottdiener WH. The 'side effects' of medicalization: a meta-analytic review of how biogenetic explanations affect stigma. Clin Psychol Rev 2013;33:782-94.

[40] Coppens E, Van Audenhove C, Scheerder G, Arensman E, Coffey C, Costa S, et al. Public attitudes toward depression and help-seeking in four European countries baseline survey prior to the OSPI-Europe intervention. J Affect Disord 2013;150:320-9.

[41] Corrigan P, Michaels PJ, Morris S. Do the effects of antistigma programs persist over time? Findings from a meta-analysis. Psychiatr Serv 2015;66:543-6.

[42] Griffiths KM, Carron-Arthur B, Parsons A, Reid R. Effectiveness of programs for reducing the stigma associated with mental disorders. A meta-analysis of randomized controlled trials. World Psychiatry 2014;13:161-75.

[43] Mehta N, Clement S, Marcus E, Stona AC, Bezborodovs N, Evans-Lacko S, et al. Evidence for effective interventions to reduce mental health-related stigma and discrimination in the medium and long term: systematic review. Br J Psychiatry 2015;207:377-84.

[44] Thornicroft G, Mehta N, Clement S, Evans-Lacko S, Doherty M, Rose D, et al. Evidence for effective interventions to reduce mental-health-related stigma and discrimination. Lancet 2016;387:1123-32.

[45] Schultze-Lutter F, Michel C, Ruhrmann S, Schimmelmann BG. Prevalence and clinical relevance of interview-assessed psychosis risk symptoms in the young adult community. Psychol Med 2017, doi:http://dx.doi.org/10.1017/ S0033291717002586.

[46] Kessler RC, Berglund P, Demler O, Jin R, Merikangas KR, Walters EE. Lifetime prevalence and age-of-onset distributions of DSM-IV disorders in the National Comorbidity Survey Replication. Arch Gen Psychiatry 2005;62:593-602.

[47] Gater R, Sousa DBAE, Barrientos G, Caraveo J, Chandrashekar CR, Dhadphale M, et al. The pathways to psychiatric care: a cross-cultural study. Psychol Med $1991 ; 21(3): 761-74$.

[48] Sheehan D, Lecrubier Y, Sheehan KH, Sheehan K, Amorim P, Janavs J, et al. Diagnostic sychiatric interview for DSM-IV and ICD-10. J Clin. Psychiatry 1998;59:22-33.

[49] Angermeyer MC, Matschinger H, Corrigan PW. Familiarity with mental illness and social distance from people with schizophrenia and major depression: testing a model using data from a representative population survey. Schizophr Res 2004;69:175-82.

[50] Link BG, Cullen FT, Frank J, Wozniak JF. The social rejection of former mental patients: understanding why labels matter. Am J Sociol 1987:92:1461-500.

[51] Brown TA. Confirmatory factor analysis for applied researchers. New York: Guilford Press; 2006.

[52] Muthén BO. Goodness of fit with categorical and other nonnormal variables. In: Bollen KA, Long JS, editors. Testing structural equation Models. Newbury Park, CA: Sage; 1993.

[53] Kline RB. Principles and practices of structural equation modelling. New York, NY: Guilford; 2011.

[54] Hooper D, Coughlan J, Mullen M. Structural equation modelling: guidelines for determining model fit. EJBRM 2008;6:53-60.

[55] Bentler PM, Bonnet DC. Significance tests and goodness of fit in the analysis of covariance structures. Psychol Bull 1980;88:588-606.

[56] Acock A. Discovering structural equation modeling using stata. Texas: Stata Press; 2013.

[57] Rosseel Y. Lavaan: an R package for structural equation modeling. J Stat Softw 2012;48:1-36. . URL: http://www.jstatsoft.org/v48/i02/.

[58] UNESCO institute for statistics. international standard classification of education, ISCED 2011. Montreal, Canada: UIS; 2012.

[59] Link BG, Yang LH, Phelan JC, Collins PY. Measuring mental illness stigma. Schizophr Bull 2004;30:511-41.

[60] Jorm AF, Griffiths KM. The public's stigmatizing attitudes towards people with mental disorders: how important are biomedical conceptualizations. Acta Psychiatr Scand 2008;118:315-21.

[61] Holzinger A, Matschinger H, Angermeyer MC. What to do about depression? Help-seeking and treatment recommendations of the public. Epidemiol Psychiatr Sci 2011;20:163-9.

[62] O'Connor PJ, Martin B, Weeks CS, Ong L. Factors that influence young people's mental health help-seeking behaviour: a study based on the Health Belief Model. J Adv Nurs 2014;70:2577-87.

[63] Yap MB, Wright A, Jorm AF. The influence of stigma on young people's helpseeking intentions and beliefs about the helpfulness of various sources of help. Soc Psychiatry Psychiatr Epidemiol 2011;46:1257-65.

[64] Eisenberg D, Downs MF, Golberstein E, Zivin K. Stigma and help seeking for mental health among college students. Med Care Res Rev 2009;66:522-41.

[65] Nederhof AJ. Methods of coping with social desirability bias: a review. Eur J Soc Psychol 1985; 15:263-80.

[66] Schultze-Lutter F, Michel C, Ruhrmann S, Schimmelmann BG. Prevalence and clinical significance of DSM-5-attenuated psychosis syndrome in adolescents and young adults in the general population: the Bern Epidemiological At-Risk (BEAR) study. Schizophr Bull 2013;40:1499-508.

[67] Alonso J, Angermeyer MC, Bernert S, Bruffaerts R, Brugha TS, Bryson H. Use of mental health services in Europe: results from the European Study of the Epidemiology of Mental Disorders (ESEMeD) project. Acta Psychiatr Scand 2004; 109:47-54.

[68] Gronholm PC, Thornicroft G, Laurens KR, Evans-Lacko S. Mental health-related stigma and pathways to care for people at risk of psychotic disorders or experiencing first-episode psychosis: a systematic review. Psychol Med 2017;47:1867-79.

[69] Cull WL, O'Connor KG, Sharp S, Tang SFS. Response rates and response bias for 50 surveys of pediatricians. Health Serv Res 2005;40:213-26.

[70] Guyll M, Spoth R, Redmond C. The effects of incentives and research requirements on participation rates for a community-based preventive intervention research study. J Prim Prev 2003;24:25-41.

[71] Ajzen I. Nature and operation of attitudes. Annu Rev Psychol 2001;52:27-58. 